ANTARCTIC GEOSCIENCE.

Symposium on Antarctic Geology and Geophysics

\section{Craddock (ed.)}

International Union of Geological Sciences, Series B, Number 4, 1172 pages. University of Wisconsin Press, 1982. Price $\$ 35.00$ U.S.

Antarctica, which covers an area in excess of that of Canada and Greenland combined, has attracted only a small section of the earth science community. Logistic problems associated with its accessibility, climate, and ice coverage require that researchers rely on "big-budget science". Nevertheless, there has been more work carried out than is generally appreciated, especially since the International Geophysical Year in 1957.

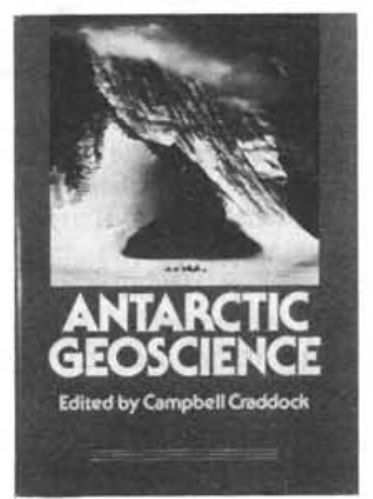

This massive volume, the last in

the old IUGS Series B, clearly displays the great increase in output of data since that time. It also illustrates the evolution of research objectives and methods, from the type linked with romanticized geologic expeditions to a more mature scientific approach. Antarctic Geoscience is the result of international cooperation between earth scientists from at least 15 countries, and is the outcome of the 3 rd Symposium of Antarctic Geology and Geophysics held in Wisconsin in 1977. It marks a milestone in the documentation of Antarctic data and Campbell Craddock, the main editor, has done the geoscience community an invaluable service. Unfortunately, the book has taken five years to complete and, to the frustration of many of the authors, publication in 1982 coincides with its successor (4th) Symposium held recently in Australia (see EPISODES, 1982/3, p. 37). Notwithstanding the editors' apologies for the delay, the impact and usefulness of the book is therefore much reduced, since many papers, notably those which are model dependent, are now outdated or have been published in updated form elsewhere.

Despite this shortcoming, this book is a gem, particularly for those unfamiliar with Antarctica as a whole; it brings together a wealth of data, which would otherwise be dispersed beyond recovery. Two hundred and twenty-eight authors have contributed 115 papers which are subdivided into 12 sections as follows: Gondwanaland (11 papers, constituting 9.2\% of the book's length), Scotia Arc Region (39, 26.3\%), East Antarctic Shield (14, 6.8\%), Upper PrecambrianPalaeozoic rocks $(11,7.8 \%)$, palaeontology $(8,5.6 \%)$, igneous rocks $(14,8.6 \%)$, structural geology and tectonics $(9,5 \%)$, mineral deposits $(4,2.6 \%)$, crustal structure $(13,6 \%)$, subglacial morphology $(4,2.5 \%)$, marine geology $(8,4.3 \%)$ and Cenozoic history $(16,9.2 \%)$.

The book's purpose, as measured by the space given to individual topics, is not entirely in accordance with its title. For reasons not disclosed, the space assigned (more than a fourth of the book) to that peripheral imbroglio of Antarctica, the Scotia Sea Region, overwhelms the agenda, even though this section contains important results from the Antarctic Peninsula. Other key topics are given scanty coverage. For example, the section on mineral resources is uninspiring and naive, except for a discussion of potential porphyry and polymetallic mineralization in the Antarctic
Peninsula by a group of Chileans with first hand knowledge of such deposits in the Andes.

Even less attention is given to Antarctica's subglacial morphology - about $98 \%$ of the continent is buried beneath a thick ice sheet with an average thickness of $2000 \mathrm{~m}$ and which may be more than $4500 \mathrm{~m}$ thick in places. This section is almost entirely devoted to the inspiring results of radioecho sounding pioneered at the Scott Polar Research Institute (U.K.) and the Technical University, Denmark, under the guidance of D. Drewry (U.K.); this account, however, lacks the excitement of their more recently published results.

The very thin coverage of important igneous rocks such as the Ferrar dolerites and the Fitzpatrick basalts (one paper), with nothing on the related Dufek massif, arguably the world's largest layered intrusion, is disappointing. This is so particularly since these rocks are a part of the vast JurassicCretaceous magmatic province, now dispersed throughout the various sectors of Gondwanaland, the framework in which this book is set. As Craddock states in the opening paper of the book:

"The geologic history of Antarctica must be studied in the context of its place in Gondwanaland ... (and) because of its central position in the reassembly, Antarctica clearly must play an important role in determining the reality and history of Gondwanaland."

This first section of the book, on Gondwanaland, unfortunately does not live up to this wisdom. It is dominated by conflicting, albeit good, papers on the geology of New Zealand and West Antarctica, but on the whole much of this section has been superceded by the 5th Gondwanaland Symposium (1980, published in 1981). There is a good summary of the marine magnetic anomaly data by I. Norton (U.S.A.), which constrains the kinematics of dispersal of the Gondwanaland fragments, but other relevant topics such as the now postulated subdivision of West-Antarctica into microplates, the correlation of late Precambrian-early Palaeozoic orogenic belts with comparable Pan-African counterparts, and the status of DuToit's Samfrau geosyncline in Antarctica, are not specifically addressed. It leaves one with an unsatisfactory feeling with regard to the present thinking on Gondwanaland. This negative impression is partly removed in the second section by several good articles dealing with comparative geology, geochemistry and geochronology of the southern Andes and the Antarctic Peninsula. Other papers report extensive data collected from the ensimatic and ensialic volcanic arcs, plutonic complexes and back-arc basins within the Scotia Arc Region, data which must be incorporated in any model dealing with the origin and development of such igneous-tectonic features.

Cenozoic volcanics are dealt with extensively throughout the book. There is a good overview on the Antarctic calcalkaline, tholeiitic and alkali-olivine basalt provinces, and several papers deal with the subantarctic volcanic islands such as St. Paul, Amsterdam and Bouvet. The geology of recent and active volcanoes on Antarctica is also adequately treated.

Apart from the review paper by G.E. Grikurov (U.S.S.R.), which gives a useful overview of the structure of Antarctica, the section on structural geology and tectonics is poor. Indeed it could have been entirely eliminated, because the few papers that are informative deal with the Transantarctic Mountain System, which is the predominant theme of another section on Upper Precambrian-Palaeozoic rocks. Most of the material in this section is clearly presented. However, one can only regret the lean coverage of this enigmatic $3000 \mathrm{~km}$ long mountain range which defines the ill-understood divide 
between East- and West-Antarctica; it is addressed only indirectly by H.R. Katz (N.Z.). Tectonic events in this belt are nebulously defined, and one is left with the feeling that there is unresolved confusion among Transantarctic geologists vis-à-vis their use of the term "orogeny", variously linked to Beardmore, Ross, Borchygrevink and Gondwanide prefixes. The papers by M.G. Laird and J.D. Bradshaw (N.Z.), and by E. Stump (U.S.A.) go some way towards clarifying these problems for the uninitiated and give some guidance to Antarctic geologists towards a solution of this thorny problem.

The section on crustal structure emphasizes the profound ignorance of the subglacial geology of this vast continent with the lack of geophysical knowledge of Antarctica. Subice geophysics must surely be one of the major frontiers remaining for earth scientists and this section serves as a gauntlet thrown before the geophysics community at large.

The section on palaeontology is a condensation of some very exciting Antarctic work; it deals sweepingly with a wide range of topics from vertebrate to micropalaeontology and palaeobotany. There are also a few important papers on the Mesozoic-Cenozoic invertebrates of the Antarctic Peninsula elsewhere in the book. Most impressive however, is the prediction by E.M. Colbert (U.S.A.) in his lucid insight into the vertebrate population of the Transantarctic mountains that "there are good reasons to expect that dinosaurs and marsupials will eventually be discovered, probably on the Antarctic Peninsula." Since this paper was written, marsupials have indeed been discovered on Seymore Island. This certainly adds credence to the quality and dedication of palacontologic work in Antarctica, and it strengthens the proposal that Antarctica served as an intermediate pathway to land-mammal dispersal between South America and Australia in the Late Cretaceous or early Cenozoic.

Soviet studies in Enderby Land imply that the earth's oldest crust formed from a melt of enderbitic (quartz-dioritic) composition, and that some of this crust is preserved over a substantial area in East Antarctica. However, the age of these rocks, variously quoted as "about $4000 \mathrm{Ma}, 4100 \pm 100$ $\mathrm{Ma}, 4000 \pm 200 \mathrm{Ma}$, is based on $\mathrm{U}$-Th-Pb isotope studies which have been seriously questioned. Nevertheless, there is a consensus of opinion that an extensive Archaean cratonic block exists in East Antarctica. Several contributors, spearheaded by Australians, show that the Prince Charles Mountains provide a magnificent section through this EastAntarctic shield. They conclude that the highest grade rocks are not, as previously assumed, necessarily the oldest rocks, and that subhorizontal tectonics must have played a prominent role in shaping the architecture of this craton. Regional recumbent structures have also been documented recently from the Napier Complex in Enderby Land, confirming this second point. The book contains also several papers presenting new observations on the East-Antarctic charnockites; of these a Japanese contribution aimed at unravelling "charnockitization" is comparable in importance to recent observations from the Indian craton.

These new findings formulate a direct challenge to the more simplistic Soviet interpretations of "geozoning", based on their reported observations from the same rock sequences. The reader is offered a unique opportunity to examine two uncompromising approaches to the deciphering of complex Archaean terrains. Although on a regional scale interpretations differ significantly due to divergent philosophical approaches to metamorphism and metasomatism, on a smaller scale more scientific differences emerge from the papers. There are clear ambiguities and misrepresentations in the detailed contributions from both schools. For example, temperature-pressure estimates in an Australian contribution on high grade gneisses, are based on experimental work which has been shown to be incorrect since 1976. Thus, the work from both schools warrants careful scrutiny. Whatever the outcome, the papers clearly indicate that, with increasing geochronologic controls, more will be heard about these regions in due course, and that East-Antarctica will play a major role towards decoding some outstanding Archaean tectonic problems.

The last two sections of the book deal in a rather sporadic and sometimes cursory manner with several topics including the morphology of the Antarctic continental shelf that has been inherited from ice erosion and sedimentation, glacial marine and glacial continental deposits, glacial geomorphology, interglacial weathering, problems related to glacial depression of the lithosphere, and glacial hydrogeology. There is a fine paper by H.J.H. Harris and K. Cartwright (U.S.A.) on fluid pressure fluctuations associated with rockglacier dynamics, and a stimulating review by $T$. Nagata (Japan) of the collection of Antarctica's meteorites and its role in understanding continental ice dynamics. There is also detailed recording of Antarctica's glacial history from both onland and offshore studies, with speculations about its influence on the growth of Northern hemisphere ice. The dynamics of Antarctic waters are traced back in time, in one paper as far back as the Oligocene-Miocene boundary when the Antarctic Circum-Polar Current was first established, ostensibly in response to the final separation of Antarctica from South America. Unfortunately this paper by P.F. Barker and J. Burell (U.K.) is buried in the section on the Scotia Arc Region.

Inevitably in a book of this nature, there is much duplication of material, but the final index is sufficiently detailed to enable the reader to locate appropriate information. Nevertheless, this duplication is at times irritating and has added considerably to the volume of the book. The time is ripe for the editor of the successor symposium to consider integrating Antarctic Geoscience into a more compact text-book. In the meantime, through his intimate knowledge of the Antarctic and ten years of planning, patience, resourcefuiness, and meticulous attentioil to detail, Campbell Craddock has produced a fine volume, clearly printed, liberal with quality maps, diagrams, photographs, tables in a text almost free of typographical errors, with standardized references attached to each paper. The references amount in total to almost 100 pages. There is an extremely useful index map of Antarctica on the inside cover, showing the areas discussed in each paper. Finally there is a bonus of a copy of Craddock's own 1:5000000 geologic map of Antarctica (published in 1972) in the back pocket. In all, this book should be considered by anyone with even a vague interest in Antarctica. In fact my advice is to get your order in now, before the publishers change their minds about the price.

\section{Maarten J. de Wit, Queen's University, Kingston, Ontario, Canada}

\section{NEW MAP OF SRI LANKA}

A new multicoloured geological map of Sri Lanka has recently been published at a scale of 1:500000. This was made possible by a generous grant from King Abdul Aziz University in Jeddah. Copies are available upon request to the compiler, Prof. P.G. Cooray at Faculty of Earth Sciences, Box 1744, Jeddah, Saudi Arabia. 


\section{THE 1980 ERUPTIONS OF MOUNT ST. HELENS, WASHINGTON}

Peter W. Lipman and Donal R. Mullineaux

Geological Survey Professional Paper 1250, 1981, 844 pp. $\$ 35.00$ (U.S.)

The volcanic eruption of Mount St. Helens on May 18, 1980 marks one of the most important events in modern volcanology. The catastrophic eruption occurred close to an area of high population, suggesting the possibility of a major disaster. In addition the eruption took place during a period of generally good weather, which allowed the close monitoring of the volcano from the very onset of its reawakening in March. As a result, this is one of the best documented of the more violent types of eruptions.

The findings have significant bearing on our understanding of eruptive processes during major volcanic events, the reliability of hazard predictions made by volcanologists, and the reaction of the authorities to those predictions when faced with a potential disaster. The question of hazard forecasting is especially relevant in the light of the conclusions of the major study by Crandell, Mullineaux and others summing up their twenty year program on volcanic hazards in the Cascades.

This massive and impressive volume reports the initial findings of many of the research teams which have been engaged in monitoring Mount St. Helens prior to, during and following the 1980 eruptions. Some 62 papers are presented in the 844 page text which is excellently produced, in keeping with the high standard of USGS publications. The book is liberally illustrated with some 120 black and white and over 40 colour photographs, as well as over 300 text figures, and 117 tables of data. A coloured 1:50000 geological map of the proximal deposits and surface features of the 1980 eruptions is included in a pocket at the back of the book.

Among the five major sections in the book, that on volcanic events comprises some five papers describing the eruptive history of Mount St. Helens prior to 1980, the chronology of the 1980 events, and eyewitness accounts of the May 18 eruption. In this section are many excellent photographs, including some 18 full page black and white oblique aerial photographs for the period March to September 1980, as well as 10 of the spectacular and now famous sequence of 21 colour photographs taken by Gary Rosenquist during the May 18 eruption.

The 23 papers in the section on geophysical monitoring reflect the increasing importance of such techniques in giving advance warning of changes in the style of activity and more particularly of forthcoming eruptions. In addition to papers on gas emissions, thermal studies and remote monitoring, there are a number dealing with seismicity. It is interesting to note that while the eruption sequence allowed a detailed characterization of precursory seismic tremors associated with andesitic-dacitic activity, no particular precursory pattern preceded the May 18 event. Other papers deal with deformation studies, previously undertaken only on basaltic volcanoes, such as Kilauea. In the case of Mount St. Helens these studies provided compelling evidence for an impending major eruption.

The section on volcanic deposits associated with the 1980 eruptions includes 22 papers dealing with the debrisavalanche of May 18 and the associated directed blast. These papers describe flow deposits generated by the melting of snow and ice; pumiceous pyroclastic flow deposits that accu- mulated on May 18 and at various times subsequent to that during 1980; lava domes which developed in the crater area; and finally the very extensive air-fall deposits. What is especially important about all these deposits is that they all can be directly correlated with specific events during the course of the eruptive history of Mount St. Helens during 1980.

Details of the effects of the eruptions are presented in seven papers, dealing with topics such as the impact upon the drainage and destruction to property and civil works, changes in river chemistry, the effects of the ash cover on soils of agricultural land, and the response of glaciers to the eruptive events.

The final five papers are concerned with analysis of potential hazards, including prediction and hazard assessments and analysis of possible effects. The eruption provided the chance to test predictions made as a result of previous extensive studies, and it is obvious from the papers presented that hazard forecasts were generally accurate, although the magnitude of the avalanche landslide and laterally directed blast had been underestimated. A number of lessons have obviously been learned.

This book of fers volcanologists a first glimpse at some of the findings of the intense investigations associated with this latest phase in the eruptive history of Mount St. Helens. The significance of these findings cannot be overestimated, nor can the value of this book to anyone who wishes to keep abreast of developments in volcanology at this very exciting time in the history of the discipline.

R.E. Bevins

National Museum of Wales, Cardiff,

\section{PROCEEDINGS OF THE FIRST REGIONA L CONFERENCE ON THE DEVE LOPMENT AND UTILIZATION OF MINERAL RESOURCES IN AFRICA}

Compiled, edited and published by the Secretariat of the UN Economic Commission for Africa, Addis Ababa, Ethiopia, 1982; 307 pages.

Available from: The Institute of Mining and Metallurgy, 44 Portland Place, London, W1N 4BR, U.K., £36. Available in French from: CIFEG, rue de Lille 103, Paris 75007, France.

This is an interesting account of the mineral resource potential of Africa and of the present poor level of utilization, together with a listing of good intentions and proposals designed to promote fuller mineral resource development. It reports on a UN conference held in Arusha, Tanzania, in February 1981. Were it to lead to concerted action by African nations and the industrial countries to tackle the problems that have been outlined now and so many times in the past, the conference would have been useful, but now nearly two years later, there is little evidence to suggest significant changes are taking place.

The publication includes the background documents prepared by the ECA Secretariat, together with eleven national papers on the present status of mineral development and a few miscellaneous contributions from observers, especially from the Academy of Sciences of the USSR. A brief summary of the final report of the conference is included. 
Despite considerable mineral resources both proven and potential, the mineral development of Africa has been severely handicapped by such factors as the scarcity of skilled manpower, weak technology capacity, lack of capital, unfavourable international märket structure and the absence of local mineral-based industries. The book documents from several viewpoints the strengths and weaknesses of the African national in their search for ways and means to overcome these handicaps and to develop their mineral resources to improve their economies.

The conference did not address the more difficult problem of how to use the benefits of mineral resources development to improve the quality of life of the poorest citizens. Likewise, little attention is paid to methods of increasing production of industrial minerals. Mineral building materials of all types are excluded though their total volume and value are great, but the practical difficulty of inadequate statistical data no doubt precludes a quantitative discussion.

Petroleum and non-fuel mineral production are considered together, though the role of OPEC in the last decade has shown how producers can influence international markets in ways not feasible for solid mineral producers because of the different international markets and the wider distribution of mineral reserves. This highlights the uncomfortable fact that often the main factor controlling successful mineral resource development may lie outside the national and even regional boundaries, since the economic situation and national interests in the industrialized countries dominate the market prices of raw materials.

The background documents generally present a reasonable and balanced view. They cover a wide range of subject matter from general reviews of mineral occurrences, exploitation and utilization, through discussions on trade, institutions, legislation, manpower and environment, to a series of specific commodity reviews covering important mineral resources of Africa. Uranium is omitted from these reviews, presumably because of its sensitive nature. Many statistical data are given up to 1978 but the usefulness of this compilation has been diminished by a number of more recent publications.

The background paper on manpower resources in the minerals industry was of particular interest to the reviewer as it makes the pertinent point that many of the presently available formal training programs are inappropriate and unsuitable for the social and economic needs of African nations. Formal skills are of little value unless attitudes to work are attuned to the existing conditions. The need for technical/vocational training at the middle and lower levels is highlighted by the shortage of technicians, which is quantitatively more acute than for engineers and scientists and forms a critical bottleneck to industrial development in Africa.

The commodity review papers give a useful summary of the mineral production in Africa and indicate probable future trends based on changing market needs, new technologies and new resources, especially sea-bed mining. The political factors affecting mineral supplies are well illustrated by the development of new ferrochrome alloys from chemical grade chromite after the 1966 UN trade embargo placed on Rhodesia, which until then was a principal source of metallurgical grade chromite.

Reading the Conference proceedings as a geoscientist one is constantly made aware that the technical problems of finding mineral resources are only the beginning of the whole cycle of exploitation that may lead to national and regional growth. But "extra-geological" problems must not be ignored and the geoscientist has an important role in contributing to their solution. The Conference recommendations recognize this in part and propose that the old institutions be reviewed and given the capability to function effectively. in a dynamic new role.

The recommendations also include a long list of suggestions, proposals and directives to overcome the difficulties that afflict the further development of mineral resources in Africa, but none of these are new. What is clearly lacking is the political and national will in Africa to effect the many changes that have been agreed and most especially the need for regional cooperation. Nor can the industrial nations (well represented by observers at the Conference) assume a complacent attitude in view of their immense economic influence on mineral resource development.

The experiences of the Eastern and Southern African Mineral Resources Development Centre at Dodoma, Tanzania, are vividly described by its Director General in his contribution to the Conference. Promises of support and participation were plentiful but delays, prevarication and even withdrawal of written undertakings have been the actual record of performance by both African and industrialized countries. It is perhaps also symptomatic of the general disinterest, that the Conference was attended by official delegations from only twenty of the fifty members of the Organization for African Unity whose 1980 Lagos Plan of Action for economic development is frequently cited in the proceedings as a blueprint for integrated regional development.

Michael Woakes Ahmadu Bello University, Nigeria

\section{THE OIL AND GAS POTENTIAL OF THE SOVIET FAR EAST}

\section{A.A. Meyerhoff}

Scientific Press Ltd., Beaconsfield, England. 1981, 176 pages; typewritten text; photo offset; soft covers. $\$ 70.00$ (U.S.)

The main conclusion of the author is "that the ultimate productive capacity of the Soviet Far East basins is limited," with all potential being off-shore and gas-prone. Even though there is a coastline of $7600 \mathrm{~km}$ length and a shelf area of about $735000 \mathrm{~km}^{2}$, less than $10^{\circ}$ barrels of recoverable oil and less than $10^{14}$ cubic feet of gas are predicted for the region. Of this amount, 460 $\times 10^{6}$ barrels of oil and $1.2 \times 10^{12}$ cubic feet of gas had been produced prior to 1978, all from the North Sakhalin Basin. Three other basins in the Soviet Far East are also regarded as having hydrocarbon potential, mainly from Miocene strata: the North Okhotsk basin, the Anadyr basin, and the Khatyrka basin. Any hydrocarbons in older strata are considered to have been destroyed by multiple diastrophism and igneous events.

The first half of the book is taken up by an overview of the stratigraphy and geological history of the region, defined as that part of the USSR east of the Lena, Aldan, Amur and Ussuri rivers. The second half enumerates details of the 
petroleum geology and structures of the individual basins.

The book does not make easy or interesting reading and will attract only those who wish to know about the petroleum geology of the region and who do not have access to the Russian literature, which comprises most of the approximately 400 references cited. Even so, as an introduction to the geology and tectonic setting of the petroleum basins of the Soviet Far East, the book has severe shortcomings, particularly in the lack of useful illustrations.

There is, however, a series of valuable palaeogeographic maps, extending from the Late Proterozoic through to the Late Cretaceous. Most geological maps and cross sections are simply reproduced from the original Russian text complete with Russian-style numbered legends. Whereas the original Russian papers explain the number legend, this book commonly does not. The result is that some maps and sections are nothing more than shapes with different styles of shading and symbols. The text also fails to overcome this illustrative weakness and is equally enigmatic.

For example (page 97): "The tectonic outline of Sakhalin island that is preferred by the writer is shown in Fig. $34 \ldots$ However the structural scheme most widely accepted is that ... reproduced as Figure 44." Both these figures as well as Figs. 23, 24, 25 and 33 - all of Sakhalin Island compiled on the same topographic base - have different unexplained shading patterns, and the reader is left mystified. This happens throughout the book, to such an extent that the serious reader will be forced to go to the original Russian texts and have to translate his own legend for the figures. Accordingly, the book is fundamentally flawed.

I suspect that this book represents a report that was commissioned by an oil company or more likely a government agency interested in the Far East of the USSR. Meyerhof $f$ compares his area of study with the adjacent U.S. territory concluding that "the potential for hydrocarbon production on the USA side of the Bering Sea still is unknown, but should be fairly good. If this prediction is correct, commercial hydrocarbons also should be found in Soviet waters. Success in American waters, therefore, may stimulate increased drilling on the Soviet side of the Sea."

C.S. Hutchison University of Malaya, Kuala Lumpur.

\section{PREDICTIVE GEOLOGY - With Emphasis on Nuclear Waste Disposal}

Ghislain de Marsily and Daniel F. Merriam (eds.)

Computers and Geology, Volume 4., Pergamon Press, Oxford, U.K., 1982, 206p. $\$ 35.00$

This volume contains thirteen papers that were presented at sessions sponsored by the International Association for Mathematical Geology at the 26th International Geological Congress in Paris, July 1980. The very thorough introduction by G. de Marsily serves not only as a good review of the individual papers included in this volume but also persuades the reader of the need for a predictive capability in geology to help define the risk involved in various natural events and the activities of man.

The first paper in the book, "Plate Tectonics as a Castrophe Theoretic Model" by R. Thom, is somewhat different from the others in that it deals with the theoretical relationship between plate tectonics and volcanism, using both mechanics and kinematics in formulating the basic approach. Rather than being predictive in the hard scientific sense it proposes a conceptual framework on which predictions of "hot spot" locations could be based.

Three papers analyze the general problem of nuclear waste disposal. The first, "Geologic Predictions and Radioactive Waste-Disposal: A Time Limit for the Predictive Requirements" by F. Gera discusses the toxicity of the main radionuclides and concludes that nuclear wastes must be isolated for periods of 50000 to 200000 years before they decay to the same level of toxicity (or less) as the natural uranium used in the fuel rods themselves. Gera points out that isolation does not necessarily have to take place in the repository but could be provided by the waste form, the waste container (and buffer material), the host rock and various retention mechanisms. He quite rightly points out that the host rock itself is the ultimate barriér.

Predictions regarding geologic processes that will affect the performance of the rock mass as a barrier require an assessment of both current and past process rates. Since these processes are deterministic and since we are concerned with short time frames compared to events such as volcanism, an assessment of risk of the release of radionuclides due to faulting, erosion, and salt dissolution can be made. Gera concludes that repositories will fill with groundwater, and hence groundwater transport is the most important process by which radionuclides can move from the repository to the biosphere. The main concern is therefore in predicting the frequency and likelihood of disruptive events that may enchance groundwater movement.

M. d'Allessandro and A. Bonne, in their application of "FaultTree Analysis" (F.T.A.) to an assessment of the suitability of a plastic clay formation as host for a nuclear waste repository, conclude that in such formations faulting could enhance groundwater movement with resultant dispersal of radionuclides. Glacial action could also result in direct release of radionuclides, and direct human intervention also poses a threat. The authors point out that the phenomena induced by the presence of the repository itself are deterministic and cannot therefore be treated by F.T.A. In addition, disruptive natural events that are slow continuous processes are not wel! suited for probabilistic treatment. However, the authors believe that F.T.A. permits a logical approach to addressing and evaluating the various scenarios for radionuclide release in a coherent system.

In a paper entitled "Long Term Prediction of the Fate of Nuclear Waste Deeply Buried in Granite," A. Barbreau and his colleagues deal specifically with transport by groundwater of radionuclides from the repository to the biosphere. The authors acknowledge that the data base that they are using is limited. Their analysis however provides a useful review of the transport and retention mechanisms that control radionuclide transport and indicates the sensitivity of each of the parameters to the migration of radionuclides at a hypothetical site.

Another group of papers deals with various aspects of the radionuclide-groundwater transport problem. Those by Brotzen and by Remson and others do not live up to their titles. The latter, which contains very few references, makes as one of its main points that in rocks that have sufficiently low permeability for use as nuclear waste repositories the fluid-flow regime will be non-Darcian and hence transport rates predicted using the solute transport equations will be orders of magnitude too large. Remson and his colleagues however do not explain how they came to this conclusion. They refer to hydraulic conductivity values of $10^{-10} \mathrm{~cm} / \mathrm{sec}$ 
but indicate neither the source of this data, nor whether it is a porous media or single fracture hydraulic conductivity, between which there is a considerable difference.

In dealing with non-Darcian flow in fractured rocks, both Remson et al. and Brotzen should note the experimental work by E.S. Romm and his colleagues (U.S.S.R.) which shows that the monolayer effect (which this reviewer assumes is what the two papers are referring to) is on the order of $500 \mathrm{~A}^{\circ}$. This means that flow in apertures at least as small as 0.1 micrometers can be described using Darcy's law. The bulk of the Remson et al. paper gives an excellent overview of the studies needed to properly characterize a potential repository site. Overall, this paper fills an important gap between the discussion by Gera and the paper by Barbreau et al. collected by other workers. Unfor tunately, data are not related to the fractures (joints, shear and fracture zones) encountered in the boreholes, and the analysis must therefore be considered incomplete. A quick review of the data indicates that there is some confusion between conductive zones and conductive test intervals. If more than one conductive zone occurs in each conductive interval then it is obvious that the spacing between conductive zones would be much less.

I. Neretnieks, in his paper deals with a specific retentive characteristic, diffusion of radionuclides from water in the fractures into the microfissures and pore spaces of a crystalline rock matrix. Neretniek's discussion is theoretical but, as he points out, if it can be proved that this mechanism is active then the rock mass will be the most effective barrier to radionuclide migration. F.W. Schwartz and F.A. Donath discuss large scale contaminant transport and the effect of both high and low conductivity fault zones on the patterns of groundwater flow and contaminant dispersion. Their analysis involves a probabilistic approach in calculating the movement of contaminants.

The other contribution on transport of radionuclides in groundwater is by J.S.Y. Wang and others who discuss the effects of the temperature produced by the decay of nuclear waste on groundwater movements. By necessity the authors deal mainly with simple fracture geometries in addition to the general porous media case.

This reviewer has included four papers in this final group: J.D. Martinez, "Salt Domes - The Past and Present, Keys to the Future"; N.-A. Morner, "Nuclear Power on Unstable Ground"; Y. Uinkovetsky and V. Rokhlin, "Quantitative Evalu- ation of the Contribution of Geologic Knowledge in Exploration for Petroleum", and G.W. Hill, "Resource-Estimation Models and Predicted Discovery".

In separate papers J.D. Martinez (on salt domes) and N.A. Morner (on unstable ground) deal with the observation of specific events in reasonable geological time frames, while contributions by Y. Uinkovetsky and V. Rokhlin and G.W. Hill review the use of geological knowledge in making predictions in the petroleum industry. The petroleum industry is clearly the source of an extensive data base that deals not only with predictions in a geological framework, with direct relevance to nuclear waste disposal, but also with direct evaluation of these predictions. It is obvious that predictions of radionuclide transport in groundwater over geological time periods must be studied under slow continuous driving forces similar to those that produced the events detailed by Martinez and Morner. This means that the studies must be carried out within the context of regional groundwater flow systems. The need is for more studies such as those of Remson and Barbreau and their colleagues, and for a focus on detailed groundwater geochemistry and isotopic studies coupled to those involving detailed physical hydrogeology. Once these data can be analyzed using three-dimensional models that produce compatible results, then we will be in a position to make predictions regarding the movement of radionuclides in flow systems over the time periods required.

Overall, this volume plays a very useful and necessary role in attempting to focus on predictions in geology, and it will be an important reference for future volumes dealing with this topic. I hope that the editors will continue their efforts in this new and rapidly evolving field. It is important that decision makers in both the political and technical fields should note carefully the introductory comment by G. de Marsily, one of the few who qualifies as both a humanist and a scientist. He states that once the risk has been def ined, "It then would be up to the people concerned by the risk or their chosen representatives to compare the various options, evaluate the advantages to the community, the cost ... and to decide whether they are willing to accept the risk involved. This decision should never be made by the risk analyst or the geologist".

J.E. Gale
Memorial University of Newfoundland,
Canada

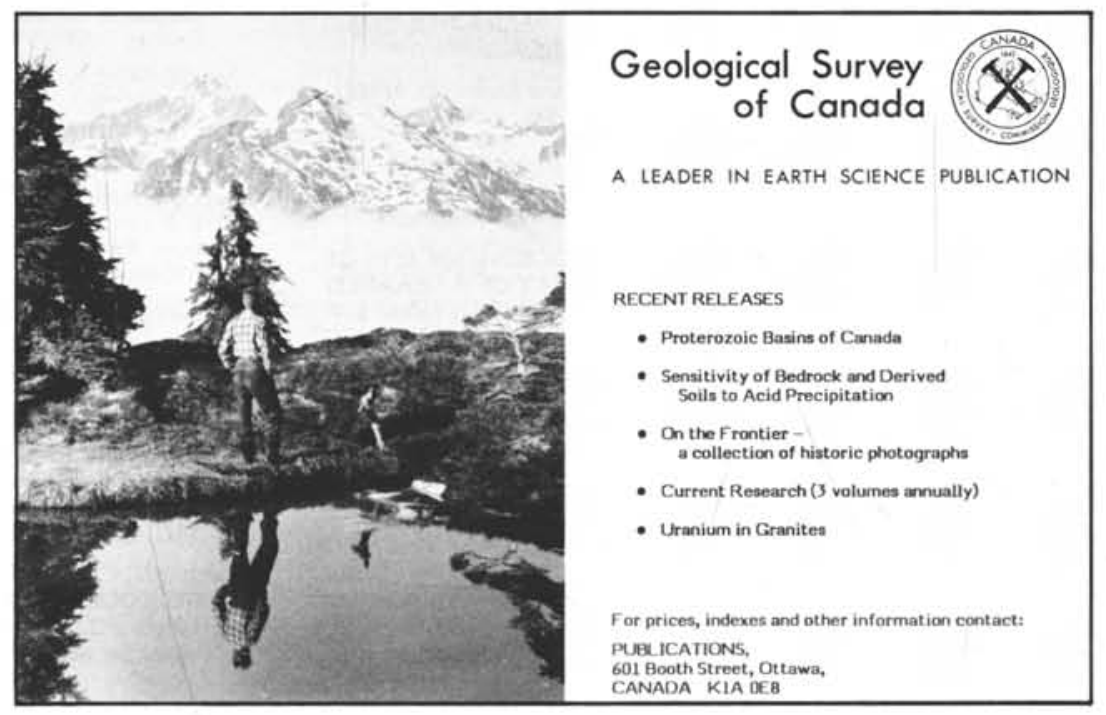

